\title{
Using Oxidized Carbon Nanotubes as Matrix for Analysis of Small Molecules by MALDI-TOF MS
}

\author{
Chensong Pan, Songyun $\mathrm{Xu}$, Ligang $\mathrm{Hu}^{*}$, Xingye $\mathrm{Su}$, Junjie $\mathrm{Ou}$, \\ Hanfa Zou, Zhong Guo, Yu Zhang, and Baochuan Guo ${ }^{+}$ \\ National Chromatographic Research and Analysis Center, Dalian Institute of Chemical Physics, \\ Chinese Academy of Sciences, Dalian, China
}

\begin{abstract}
Oxidized carbon nanotubes are tested as a matrix for analysis of small molecules by matrix assisted laser desorption/ionization time of flight mass spectrometry (MALDI-TOF-MS). Compared with nonoxidized carbon nanotubes, oxidized carbon nanotubes facilitate sample preparation because of their higher solubility in water. The matrix layer of oxidized carbon nanotubes is much more homogeneous and compact than that of nonoxidized carbon nanotubes. The efficiency of desorption/ionization for analytes and the reproducibility of peak intensities within and between sample spots are greatly enhanced on the surface of oxidized carbon nanotubes. The advantage of the oxidized carbon nanotubes in comparison with $\alpha$-cyano-4-hydroxycinnamic acid (CCA) and carbon nanotubes is demonstrated by MALDITOF-MS analysis of an amino acid mixture. The matrix is successfully used for analysis of synthetic hydroxypropyl $\beta$-cyclodextrin, suggesting a great potential for monitoring reactions and for product quality control. Reliable quantitative analysis of jatrorrhizine and palmatine with a wide linear range (1-100 $\mathrm{ng} / \mathrm{mL}$ ) and good reproducibility of relative peak areas (RSD less than $10 \%)$ is achieved using this matrix. Concentrations of jatrorrhizine $(8.65 \mathrm{mg} / \mathrm{mL})$ and palmatine $(10.4 \mathrm{mg} / \mathrm{mL})$ in an extract of Coptis chinensis Franch are determined simultaneously using the matrix and a standard addition method. (J Am Soc Mass Spectrom 2005, 16, 883-892) @ 2005 American Society for Mass Spectrometry
\end{abstract}

$\mathrm{M}$ atrix assisted laser desorption/ionization time of flight mass spectrometry (MALDI-TOFMS) $[1,2]$ could provide not only the molecular weight of large molecules, such as protein, DNA/ RNA, polysaccharides, polymer and so on [3-8], but also the structural information of molecules to identify the sequence by the post source decay (PSD) [9-12] technique with high speed, accuracy, and sensitivity. Recently, MALDI-TOF-MS has also been developed to analyze small molecules [13] successfully by using the different matrix substances, such as desorption/ionization on porous silicon (DIOS) [14-17], matrix with high molecular weight $[18,19]$, surfactant suppressed matrix [20], inorganic materials [21-25], etc. Though considerable works of quantitative determination using MALDI have been well documented and reviewed [26], quantitative analysis by MALDI is still considered as a relatively unreliable technique for the limiting factor of

Published online April 15, 2005

Address reprint requests to Dr. H. Zou, National Chromatographic Research and Analysis Center, Dalian Institute of Chemical Physics, Chinese Academy of Sciences, 457 Zhongshan Road, Dalian 116023, China. E-mail: hanfazou@dicp.ac.cn and hanfazou@dicp.ac.cn

* Also at the Research Center for Eco-Environmental Science, Chinese Academy of Sciences, Beijing 100085, China.

† Also at the Department of Chemistry, Cleveland State University, Cleveland, $\mathrm{OH} 44115$, USA. reproducibility within and between sample spots. Recently, Siuzdak and coworkers [27] developed a method for quantitative analysis of small molecules with desorption/ionization on porous silicon using electrospray deposition of analytes, and a quite good quantitative result with linear calibrations $R^{2}>0.99$ and values of RSD $<7 \%$ was achieved. It is believed that MALDI could be a powerful technique to provide both qualitative and quantitative determination of small compounds.

Carbon nanotubes have been attracting wide interest $[28,29]$ of scientists since they were initially discovered by Iijima et al. [30, 31]. Recently, Carbon nanotubes have been developed as the matrix for MALDI-TOF-MS for analysis of small molecules [25], in which carbon nanotubes function both as the energy receptacle for laser radiation and as the energy transporter for desorption/ionization of analytes with the minimization of interference signals caused by matrix ion. The effectiveness of the method as matrix has been demonstrated by several compounds with low molecular weight. However, the low solubility of carbon nanotubes in water or organic solvent makes it hard to deposit carbon nanotubes onto the sample target and to form a homogeneous layer of matrix, leading to the relatively poor reproducibility and resolution of peaks for analytes. 
Moreover, after most of the solvent was evaporated, carbon nanotubes could not attach to the sample target tightly and hence, easily fly off from the sample target under vacuum, which may cause the contamination of the ion source. In the end, the efficiency of desorption/ ionization for analytes on matrix layer of carbon nanotubes is still not satisfactory for the impurities in raw product of carbon nanotubes, such as amorphous carbon, graphite pieces, and catalytic metal particles. These impurities may block the energy transferring for desorption/ionization of analytes.

The oxidation and further chemical functionalization of carbon nanotubes pioneered a new way to the research and application of oxidized carbon nanotubes [32-36]. Recently, Ugarov et al. [35] showed that the acidic derivatized fullerenes and single wall nanotubes could be efficient matrices for MALDI-TOF-MS. Here, we developed oxidized carbon nanotubes as the matrix for MALDI-TOF-MS for the analysis of small molecules. After the oxidation procedure, carbon nanotubes were purified and cut into shortened nanotubes attached with carboxylic groups (-COOH, $-\mathrm{COONa}$, or $-\mathrm{COOK})$ $[32,33]$. Compared with nonoxidized carbon nanotubes [25], ${ }^{\circ}$ oxidized $^{\circ}$ carbon $^{\circ}$ nanotubes ${ }^{\circ}$ facilitate $^{\circ}$ sample $^{\circ}$ preparation because of their higher solubility in water. The efficiency of desorption/ionization for analytes and the reproducibility of peak intensities within and between sample spots are greatly enhanced on the surface of oxidized carbon nanotubes. Consequently, reliable quantitative analysis of jatrorrhizine and palmatine with a wide linear range and good reproducibility of relative peak areas are achieved using this matrix. Finally, the concentrations of jatrorrhizine and palmatine in an extract of Coptis chinensis Franch are determined simultaneously using the matrix and the standard addition method.

\section{Experimental}

\section{Chemicals and Materials}

Multiwalled carbon nanotubes were kindly offered by Professor F. Wei (Tsinghua University, Beijing, China). Matrix of $\alpha$-cyano-4-hydroxycinnamic acid (CCA) and trifluoroacetic acid (TFA) was purchased from Sigma (St. Louis, MO). Amino acids of Asn, Glu, His, and Phe were purchased from Fluka (Buchs, Switzerland). Quinine, $\beta$-cyclodextrin $(\beta-\mathrm{CD})$ and epoxy propane were purchased from Shanghai Chemical Factory (Shanghai, China). Berberine, hydrochloride, jatrorrhizine hydrochloride, and palmatine hydrochloride were purchased from the National Institute for the Control of Pharmaceutical and Biological Products (Beijing, China). The traditional Chinese medicines, Coptis chinensis Franch (root), was purchased from a local Chinese medicine store (Dalian, China). Other reagents were analytical grade with the exception of ethanol and acetonitrile, which were HPLC grade. The water used in all exper- iments was prepared from a Milli-Q water purification system (Millipore, Milford, MA).

\section{Procedures for Oxidization of Carbon Nanotubes}

Briefly, $200 \mathrm{mg}$ carbon nanotubes were placed into the mixture of concentrated $\mathrm{HNO}_{3}$ and $\mathrm{H}_{2} \mathrm{SO}_{4}(10 \mathrm{~mL} / 30$ $\mathrm{mL}, 1 / 3$ ) by stirring and refluxing at $120^{\circ} \mathrm{C}$ for $30 \mathrm{~min}$; then the solution was cooled to room temperature and diluted to $300 \mathrm{~mL}$ with water, filtrated through a 0.45 $\mu \mathrm{m}$ membrane, and rinsed with water untill the $\mathrm{pH}$ value approached to 7 . Then, the oxidized carbon nanotubes with the membrane were transferred into 50 $\mathrm{mL}$ ethanol, and after sonication for $1 \mathrm{~min}$, the membrane was removed from the solution of oxidized carbon nanotubes in ethanol. After ethanol was carefully heated to its boiling point and evaporated, about $30 \mathrm{mg}$ oxidized carbon nanotubes were collected and stored at dry condition for further use.

\section{Preparation of Analyte Solution}

Amino acids of Asn, Glu, His, and Phe were all dissolved in water at the concentration of $10 \mathrm{mM}$ as storage solution, respectively, and the mixture solution of the 4 amino acids (4AA) was obtained by mixing storage solution and diluting with water to the concentration of $1.0 \mathrm{mM}$ each. The storage solution for quinine, berberine, jatrorrhizine, and palmatine were prepared by dissolving them in water at the concentration of 0.1 $\mathrm{mg} / \mathrm{mL}$, respectively, and sample solution with other different concentrations were diluted step by step. All storage solution was refrigerated at around $4{ }^{\circ} \mathrm{C}$ for further use.

\section{Synthesis of Hydroxypropyl $\beta$-Cyclodextrin}

Hydroxypropyl $\beta$-cyclodextrin is the synthetic product of $\beta$-cyclodextrin $(\beta-C D)$ reacted with epoxy propane. $1.14 \mathrm{~g} \beta$-CD was dissolved in $40 \mathrm{~mL}$ solution of $5 \%$ sodium hydroxide at room temperature and cooled down in an ice bath untill the temperature was below $0{ }^{\circ} \mathrm{C}$. Then, $3 \mathrm{~mL}$ epoxy propane was gradually added to the $\beta$-CD solution. After stirring overnight in the ice bath, the reaction solution was adjusted to neutral. Then, most of the solvent was distilled at reduced pressure to get the amorphous product of hydroxypropyl $\beta$-cyclodextrin. The synthetic product of hydroxypropyl $\beta$-cyclodextrin was then redissolved in water at the concentration of $1 \mathrm{mg} / \mathrm{mL}$, and $1 \mu \mathrm{L}$ solution was pipetted onto the matrix layer of oxidized carbon nanotubes to perform a MALDI-TOF-MS analysis.

\section{Preparation of Extract of Coptis chinensis Franch}

About 15 g Coptis chinensis Franch was crushed into powder in a grinder and immersed in $150 \mathrm{~mL} \mathrm{30 \%}$ ethanol overnight. After boiling for $1.5 \mathrm{~h}$, the extract 
was filtered through a $0.45 \mu \mathrm{m}$ membrane and distilled at reduced pressure. The residues were redissolved in $25 \mathrm{~mL}$ water and stored at a temperature of about $4{ }^{\circ} \mathrm{C}$ for further experiments.

\section{Sample Preparation for MALDI-TOF-MS}

Matrix of CCA was prepared as a saturated solution in TA $(0.1 \%$ TFA in water/acetonitrile, 2/1, vol/vol). 2.0 $\mathrm{mg}$ carbon nanotubes were dispersed in the $0.5 \mathrm{~mL}$ solution of ethanol/water (1/1, vol/vol) with sonication for $3 \mathrm{~min}$ and $1 \mu \mathrm{L}$ solution was pipetted on the sample target quickly. The matrix solution of oxidized carbon nanotubes was prepared by dissolving them in water with sonication for $3 \mathrm{~min}$ at a concentration of about $1 \mathrm{mg} / \mathrm{mL}$. $1 \mu \mathrm{L}$ solution of matrix was pipetted onto the sample target and left in air at room temperature for 5 to $10 \mathrm{~min}$ to form a thin layer of matrix by evaporating water. Then $1 \mu \mathrm{L}$ solution of analyte was pipetted onto the layer of matrix and left in air for 5 to $10 \mathrm{~min}$ for evaporation of the solvent and for further analysis by MALDI-TOF-MS.

\section{Instrumentation}

Carbon nanotubes and oxidized carbon nanotubes were characterized by transmission electronic microscopy (TEM, JEM-2000EX) operated at $100 \mathrm{kV}$. The FT-IR spectra were collected by a NEXUS 670 (Thermo Nicolet, Madison, WI) with the reflectance mode. Mass spectrometry was performed on the Bruker Autoflex (Bruker Daltonics, Bremen, Germany). The instrument was equipped with a nitrogen laser $(\lambda=337 \mathrm{~nm})$ and its available accelerating potential was in the range of $+20 /-20 \mathrm{kV}$. The MALDI uses a ground-steel sample target with 384 spots. The analytical range of laser energy was adjusted to slightly above the threshold to obtain good resolution and signal-to-noise ratio $(\mathrm{S} / \mathrm{N})$. Unless otherwise noted, all mass spectra shown were obtained in the positive-ion reflection mode with delayed extraction for $40 \mathrm{~ns}$, and each spectrum was accumulated by 20 laser shots typically. External mass calibration was obtained by using two points that bracketed the mass range of interest.

\section{Result and Discussion}

\section{Methodology}

Figure $^{\circ} 1^{\circ}$ shows $^{\circ}$ the ${ }^{\circ}$ TEM $^{\circ}$ images $^{\circ}$ of ${ }^{\circ}\left(\text { Figure }^{\circ} 1 \mathrm{a}\right)^{\circ}$ carbon nanotubes ${ }^{\circ}$ and $^{\circ}\left(\text { Figure }^{\circ} 1 \mathrm{~b}\right)^{\circ}$ oxidized $^{\circ}$ Carbon $^{\circ}$ nanotubes in a magnification of 50,000. The oxidized carbon nanotubes seem to be thinner, rougher, and shorter after oxidization because the exterior walls of multiwall carbon nanotubes were oxidized and the long tubes were cut into shortened ones. Furthermore, the FT-IR spectrum of carbon nanotubes and oxidized carbon nanotubes, ${ }^{\circ}$ as $^{\circ}$ shown $^{\circ}$ in $^{\circ}$ Figure $^{\circ} 2,{ }^{\circ}$ shows $^{\circ}$ that ${ }^{\circ}$ the $^{\circ}$ carboxylic groups $(-\mathrm{COOH},-\mathrm{COONa}$, or $-\mathrm{COOK})$ were introduced onto carbon nanotubes through the oxidation process by the increase of peaks at $3490 \mathrm{~cm}^{-1}$ $(\mathrm{O}-\mathrm{H})$ and $1600 \mathrm{~cm}^{-1}(\mathrm{C}=\mathrm{O})$. So it is believed that carbon nanotubes were cut into thinner, rougher and shorter pieces with carboxylic groups on their surface after oxidation.

Figure $^{\circ} 3 \mathrm{a}^{\circ}$ shows $^{\circ}$ the $^{\circ}$ comparison $^{\circ}$ of $^{\circ}$ solubility $^{\circ}$ of carbon nanotubes in water before and after oxidization procedure. Carbon nanotubes both before and after oxidization procedure were dispersed in water with sonication for $3 \mathrm{~min}$ and rested for $48 \mathrm{~h}$ at room temperature. Carbon nanotubes were all deposited in the bottom of flask after a few minutes of sonication due to their dramatically hydrophobic surface, but the oxidized carbon nanotubes were still well dispersed in water even after centrifugation at 5,000 rpm for $10 \mathrm{~min}$. The solubility of oxidized carbon nanotubes in water is determined at the concentration of approximately 1.0 $\mathrm{mg} / \mathrm{mL}$. The solubility we obtained is much higher than that of functionalized single wall nanotubes measured ${ }^{\circ}$ by $^{\circ} \mathrm{Ugarov}^{\circ} \mathrm{et}^{\circ}$ al. $^{\circ}[35]^{\circ}$, because $^{\circ}$ the $^{\circ}$ solubility $^{\circ}$ of oxidized carbon nanotubes in water depends on the degree of oxidation; in other words, it is greatly affected by the property of nanotubes (bent or unbent, multiwall or single wall), the intensity of oxidant, and the reaction

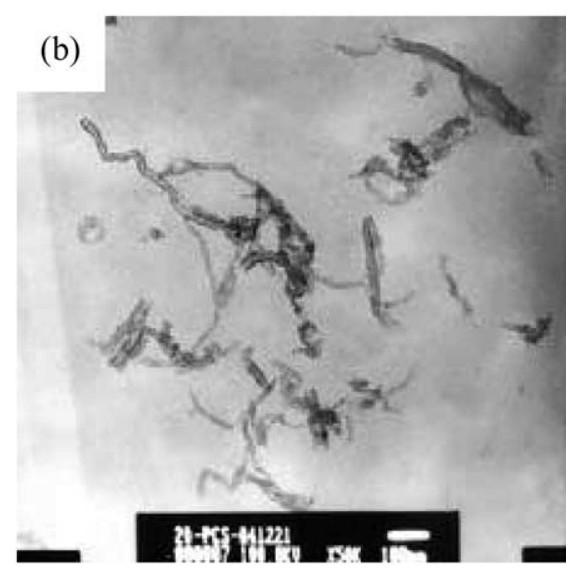

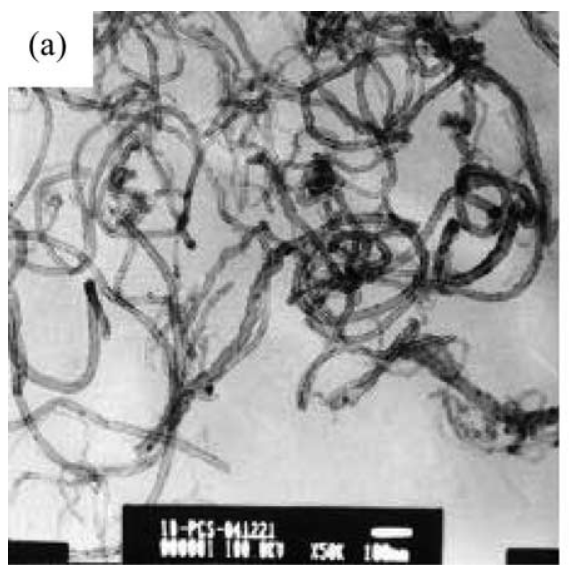

Figure 1. TEM images $(\times 50,000-$ fold $)$ of $(\mathbf{a})$ carbon nanotubes and $(\mathbf{b})$ oxidized carbon nanotubes. 


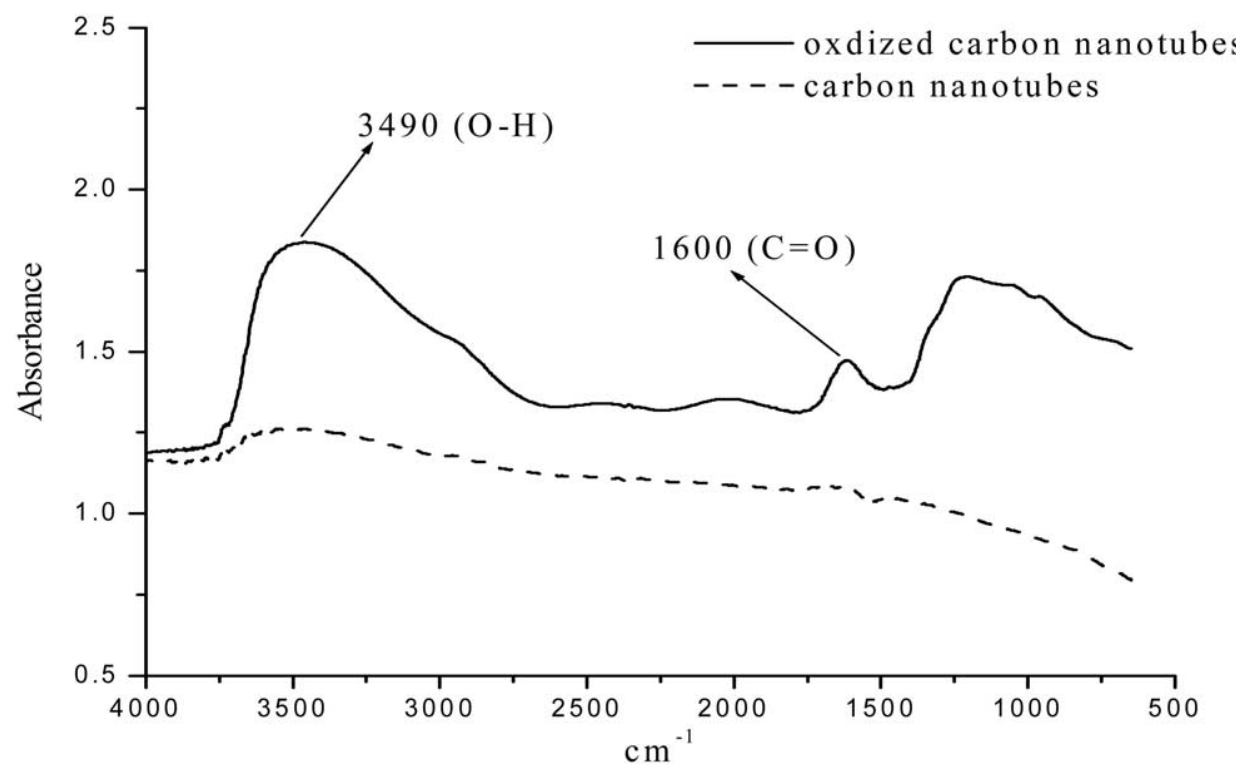

Figure 2. FT-IR (reflectance mode) spectrum of carbon nanotubes and oxidized carbon nanotubes.

time. As a result, the solubility depends on the size of the particle and the amount of hydrophilic group introduced after oxidation. So, it is assumed that those oxidized carbon nanotubes we obtained are much smaller in size and are attached with more hydrophilic groups than those of Ugarov et al.

Because of the insolubility of carbon nanotubes in water or organic solvent, it is hard to control the amount of carbon nanotubes deposited onto the sample target. This limitation was overcome by the oxidized carbon nanotubes with their good solubility in water. Figure $3 b^{\circ}$ shows $^{\circ}$ the ${ }^{\circ}$ comparison $^{\circ}$ of $^{\circ}$ the $e^{\circ}$ matrix ${ }^{\circ}$ layers ${ }^{\circ}$ of carbon nanotubes and oxidized carbon nanotubes on the sample target, which were formed after most solvent was evaporated at room temperature in air for 5-10 min. The matrix layer formed by oxidized carbon nanotubes is visibly more homogeneous than that formed by carbon nanotubes. Moreover, the matrix layer formed by carbon nanotubes is so incompact that they will easily fly off from the sample target under vacuum and cause the contamination of the ion source. In contrast, the matrix layer formed by oxidized carbon nanotubes attaches to the sample target so tightly that it could not be rinsed out from the sample target by water or ethanol; the layer could only be scraped off by water-immersed cotton.

Figure ${ }^{\circ} 4^{\circ}$ shows $^{\circ}$ the ${ }^{\circ}$ mass $^{\circ}$ spectra ${ }^{\circ}$ for ${ }^{\circ}$ an $^{\circ}$ amino ${ }^{\circ}$ acid mixture ${ }^{\circ}$ containing ${ }^{\circ} \mathrm{Asn},{ }^{\circ} \mathrm{Glu},{ }^{\circ} \mathrm{His}^{\circ}{ }^{\circ}$ and $^{\circ} \mathrm{Phe}^{\circ}$ in $^{\circ}$ (Figure $4 a)^{\circ}$ the $^{\circ} \mathrm{LDI}^{\circ}$ mode $^{\circ}$ without $^{\circ}$ any ${ }^{\circ}$ matrix $^{\circ}$ and $^{\circ}$ MALDI mode $^{\circ}$ with $^{\circ}$ matrix $^{\circ}$ of ${ }^{\circ}\left(\text { Figure }^{\circ} 4 \mathrm{~b}\right)^{\circ} \mathrm{CCA}^{\circ}{ }^{\circ}\left(\right.$ Figure $^{\circ} 4 \mathrm{c}$ ) carbon $^{\circ}$ nanotubes, ${ }^{\circ}$ and $^{\circ}\left(\text { Figure }^{\circ} 4 \mathrm{~d}\right)^{\circ}$ oxidized $^{\circ}$ carbon nanotubes, in which concentration of each compound is at $1 \mathrm{mM}$. It is noted that there were no signals of analytes ${ }^{\circ}$ in $^{\circ}{ }^{\circ}$ igure ${ }^{\circ} 4 a^{\circ}$ with $^{\circ} \mathrm{LDI}^{\circ}$ mode, ${ }^{\circ}$ and $^{\circ}$ all ${ }^{\circ} 4^{\circ}$ amino acids ${ }^{\circ}$ were ${ }^{\circ}$ detected ${ }^{\circ}{ }^{\circ}{ }^{\circ}$ Figure $4 \mathrm{~b}^{\circ}{ }^{\circ} \mathrm{s}^{\circ}\left[\mathrm{M}^{\circ}+{ }^{\circ} \mathrm{H}\right]^{+{ }^{\circ}}$ (Asn, 133; Glu, 148; His, 156; and Phe, 166) with conventional matrix of CCA, but a strong interference of background is caused by matrix of CCA. It is also visible that peaks for Asn $\left(155,[\mathrm{M}+\mathrm{Na}]^{+}\right.$; 171, $\left.[\mathrm{M}+\mathrm{K}]^{+}\right)$, Glu (186, [M $\left.+\mathrm{K}]^{+}\right)$, His $\left(156,[\mathrm{M}+\mathrm{H}]^{+} ; 178,[\mathrm{M}+\mathrm{Na}]^{+} ; 194,[\mathrm{M}+\right.$ $\left.\mathrm{K}]^{+}\right)$, and Phe $\left(188,[\mathrm{M}+\mathrm{Na}]^{+} ; 204,[\mathrm{M}+\mathrm{K}]^{+}\right)$are all well ${ }^{\circ}$ detected ${ }^{\circ}$ with $^{\circ}$ the ${ }^{\circ}$ matrix ${ }^{\circ}$ of ${ }^{\circ}$ oxidized $^{\circ}{ }^{\circ}$ carbon ${ }^{\circ}$ nanotubes $^{\circ}$ as $^{\circ}$ shown $^{\circ}{ }^{\circ}{ }^{\circ}$ Figure $^{\circ} 4 \mathrm{~d},{ }^{\circ}$ while ${ }^{\circ}$ only ${ }^{\circ}$ peaks ${ }^{\circ}$ for ${ }^{\circ} \mathrm{His}$ $\left(156,[\mathrm{M}+\mathrm{H}]^{+} ; 178,[\mathrm{M}+\mathrm{Na}]^{+} ; 194,[\mathrm{M}+\mathrm{K}]^{+}\right)$, Asn $\left(171,[\mathrm{M}+\mathrm{K}]^{+}\right)$are observed with matrix of carbon nanotubes ${ }^{\circ}$ as $^{\circ}$ shown $^{\circ}$ in $^{\circ}$ Figure $^{\circ} 4 \mathrm{c}^{\circ}{ }^{\circ}$ Compared $^{\circ}$ with carbon nanotubes, the intensity and $\mathrm{S} / \mathrm{N}$ of peaks and the efficiency of desorption/ionization for analytes on oxidized carbon nanotubes are greatly enhanced. The improvement may be attributed to the following factors: one is that most of impurities in the raw product of carbon nanotubes were oxidized and removed after oxidation. The other is that introduced carboxylic groups $(-\mathrm{COOH},-\mathrm{COONa}$, or $-\mathrm{COOK})$ on oxidized carbon nanotubes could provide analytes with a greater amount of $\mathrm{H}^{+}, \mathrm{Na}^{+}$, or $\mathrm{K}^{+}$to form adducts of $[\mathrm{M}+$ $\mathrm{H}]^{+},[\mathrm{M}+\mathrm{Na}]^{+}$, or $[\mathrm{M}+\mathrm{K}]^{+}$during the process of desorption/ionization. The importance of multiple carboxylic groups attached to oxidized carbon nanotubes for the matrix operation is also demonstrated by Uga$\operatorname{rov}^{\circ}{ }^{\circ} t^{\circ} a .^{\circ}[35] .{ }^{\circ}$ In ${ }^{\circ}$ addition, ${ }^{\circ}$ no $^{\circ}$ fragmentation ${ }^{\circ}$ of ${ }^{\circ}$ analyte ion $^{\circ}$ is ${ }^{\circ}$ observed ${ }^{\circ}$ in $^{\circ}$ Figure $^{\circ} 4 \mathrm{~d},{ }^{\circ}$ suggesting ${ }^{\circ}$ that $^{\circ}$ oxidized carbon nanotubes should be a "soft" matrix for MALDITOF-MS.

The mass spectrum of the synthetic product of hydroxypropyl $^{\circ} \beta$-cyclodextrin ${ }^{\circ}$ is ${ }^{\circ}$ shown $^{\circ}$ in $^{\circ}$ Figure $^{\circ} 5,{ }^{\circ}$ in which a series of compounds of hydroxypropyl $\beta$-cyclodextrin with an interval of $58 \mathrm{Da}$ are determined by the MALDI-TOF-MS with matrix of oxidized carbon nanotubes. Peaks of $m / z$ at 1390, 1448, 1506, 1564, 1622, $1680,1738,1796,1854$, and 1912 could be assigned to the $\mathrm{Na}^{+}$adduct ions for one molecule of $\beta$-CD reacted with $\mathrm{n}(\mathrm{n}=4, \ldots, 13)$ molecules of epoxy propane, and peaks of $\mathrm{m} / \mathrm{z}$ at $1464,1522,1580,1638,1696,1754,1812$, and 

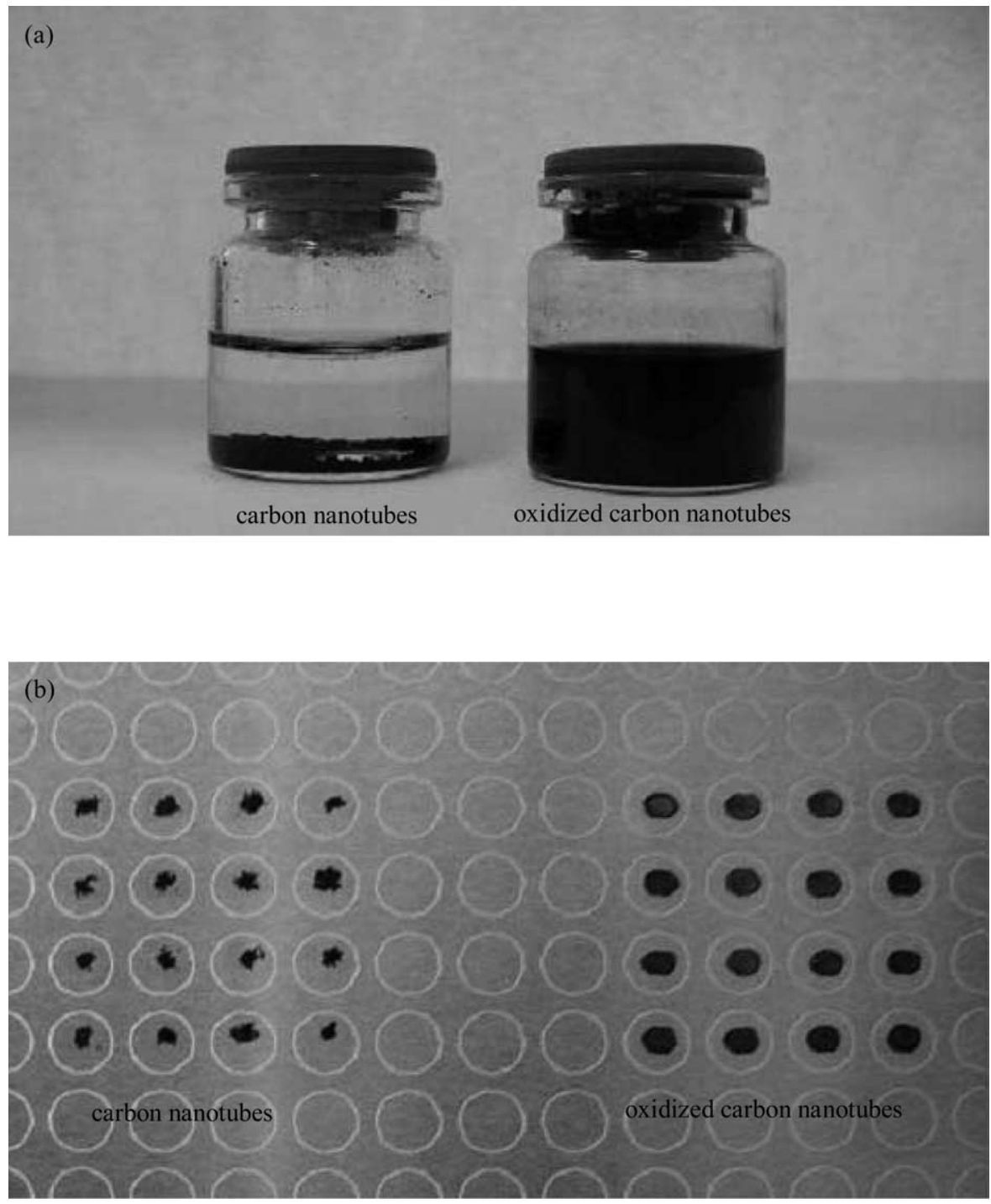

Figure 3. Comparison of (a) the solubility of carbon nanotubes and oxidized carbon nanotubes in water, and (b) the matrix layers of carbon nanotubes and oxidized carbon nanotubes. All matrix layers were formed after evaporating solvent by pipetting $1 \mu \mathrm{L}$ of matrix solution onto the sample target.

1870 could belong to the $\mathrm{K}^{+}$adduct ions for one molecule of $\beta$-CD reacted with $\mathrm{n}(\mathrm{n}=5, \ldots, 12)$ molecules of epoxy propane. The peak for $\beta$-CD (1136, $[\mathrm{M}+\mathrm{H}]^{+} ; 1158,\left[\mathrm{M}+\mathrm{Na}^{+}\right.$, or $1174,[\mathrm{M}+\mathrm{K}]^{+}$) were also not detected in mass spectrum, which demonstrated that $\beta$-CD was reacted with epoxy propane and transferred to hydroxypropyl $\beta$-cyclodextrin with the number of substituted groups from 4 to 13 under this reaction condition.

\section{Reproducibility Within and Between Sample Spots}

As the matrix layer formed by oxidized carbon nanotubes is more homogeneous than that formed by carbon nanotubes, the reproducibility of peak intensities for analyte is improved greatly. Take quinine (325, [M + $\mathrm{H}^{+}$) at the concentration of $0.01 \mathrm{mg} / \mathrm{mL}$ as an example; the relative standard deviation (RSD) value of peak intensities for quinine within one sample spot by averaging for 10 spectra is around $30 \%$ with matrix of carbon nanotubes, while the RSD value is down to $5 \%$ with matrix of oxidized carbon nanotubes. The RSD value of peak intensities for quinine between five sample spots is around $25 \%$ with matrix of carbon nanotubes, while the RSD value is only $5 \%$ with matrix of oxidized carbon nanotubes. The peak intensity for quinine is also averaged for 10 spectra in one sample spot. This reliable reproducibility within and between sample spots provides a solid foundation for quantitative analysis of small molecules of interest in practice as long as a proper internal standard (IS) is selected.

\section{Quantitative Analysis}

Berberine, jatrorrhizine, and palmatine are three of the bioactive alkaloids in traditional Chinese medicines 

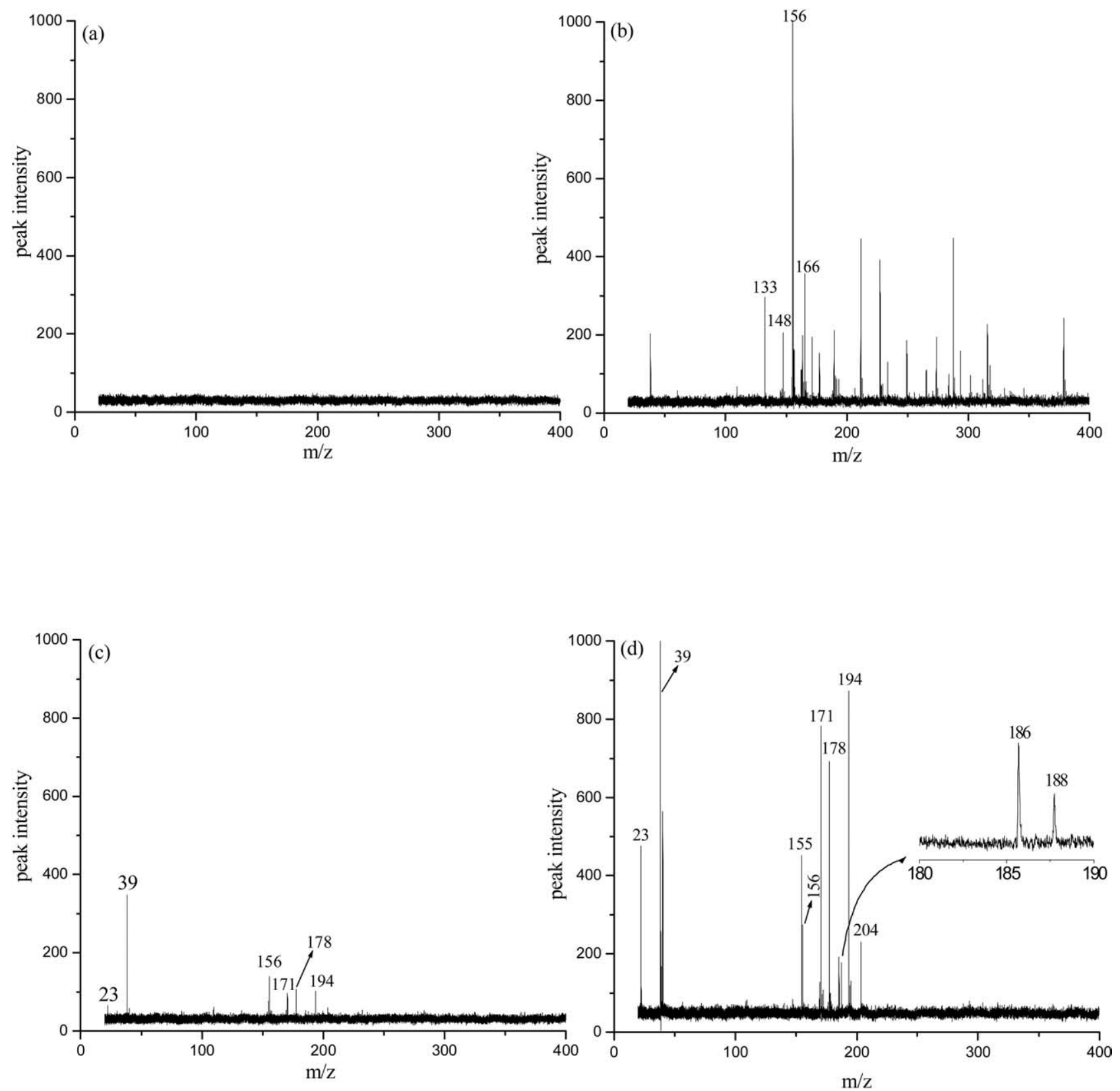

Figure 4. Mass spectra for 4 amino acid mixture solution containing Asn $\left(133,[\mathrm{M}+\mathrm{H}]^{+} ; 155,[\mathrm{M}+\right.$ $\left.\mathrm{Na}]^{+} ; 171,[\mathrm{M}+\mathrm{K}]^{+}\right)$; Glu $\left(148,[\mathrm{M}+\mathrm{H}]^{+} ; 170,[\mathrm{M}+\mathrm{Na}]^{+} ; 186,[\mathrm{M}+\mathrm{K}]^{+}\right)$; His $\left(156,[\mathrm{M}+\mathrm{H}]^{+} ; 178\right.$, $\left.[\mathrm{M}+\mathrm{Na}]^{+} ; 194,[\mathrm{M}+\mathrm{K}]^{+}\right)$; and Phe $\left(166,[\mathrm{M}+\mathrm{H}]^{+} ; 188,[\mathrm{M}+\mathrm{Na}]^{+} ; 204,[\mathrm{M}+\mathrm{K}]^{+}\right)$in the (a) LDI mode without matrix, and with matrix of (b) CCA, (c) carbon nanotubes, and (d) oxidized carbon nanotubes. $1 \mu \mathrm{L}$ sample solution was deposited on the target spots by keeping concentrations of all analytes at $1.0 \mathrm{mM}$.

(TCMs). For their similarity in molecular structure, herein, we selected berberine $\left(337,[\mathrm{M}+\mathrm{H}]^{+}\right)$as the IS and the other two, jatrorrhizine $\left(339,[\mathrm{M}+\mathrm{H}]^{+}\right)$and palmatine $\left(353,[\mathrm{M}+\mathrm{H}]^{+}\right)$as the analytes, to perform the quantitative analysis by MALDI-TOF-MS with matrix of oxidized carbon nanotubes. The concentrations of two analytes in the solution are simultaneously varied from 1 to $100 \mathrm{ng} / \mathrm{mL}$ while the concentration of IS is kept constant at $100 \mathrm{ng} / \mathrm{mL}$. The obtained quantitative calibration curves between the relative area
( $\left.\mathrm{A}_{\text {analytes }} / \mathrm{A}_{\mathrm{IS}}\right)$ of analyte peaks to IS peak and concentrations ${ }^{\circ}$ of $^{\circ}$ analytes ${ }^{\circ}$ are $^{\circ}$ shown ${ }^{\circ}{ }^{\circ}$ Figure $^{\circ} 6$. $^{\circ}$ Every ${ }^{\circ} \operatorname{dot}^{\circ}$ in Figure ${ }^{\circ} 6^{\circ}$ is ${ }^{\circ}$ the ${ }^{\circ}$ average $e^{\circ}$ of ${ }^{\circ} 5^{\circ}$ spectra, ${ }^{\circ}$ and ${ }^{\circ}$ each ${ }^{\circ}$ spectrum is accumulated from 20 laser shots at 10 different laser spots, i.e., 200 laser shots total for each. The $\mathrm{R}^{2}$ values for quantitative calibration curves of jatrorrhizine and palmatine are 0.9859 and 0.9898 , respectively. The linear range of calibration curves for jatrorrhizine and palmatine in solution are about $1-100 \mathrm{ng} / \mathrm{mL}$. The RSD values for each dot are less than $10 \%$ except the dot for 


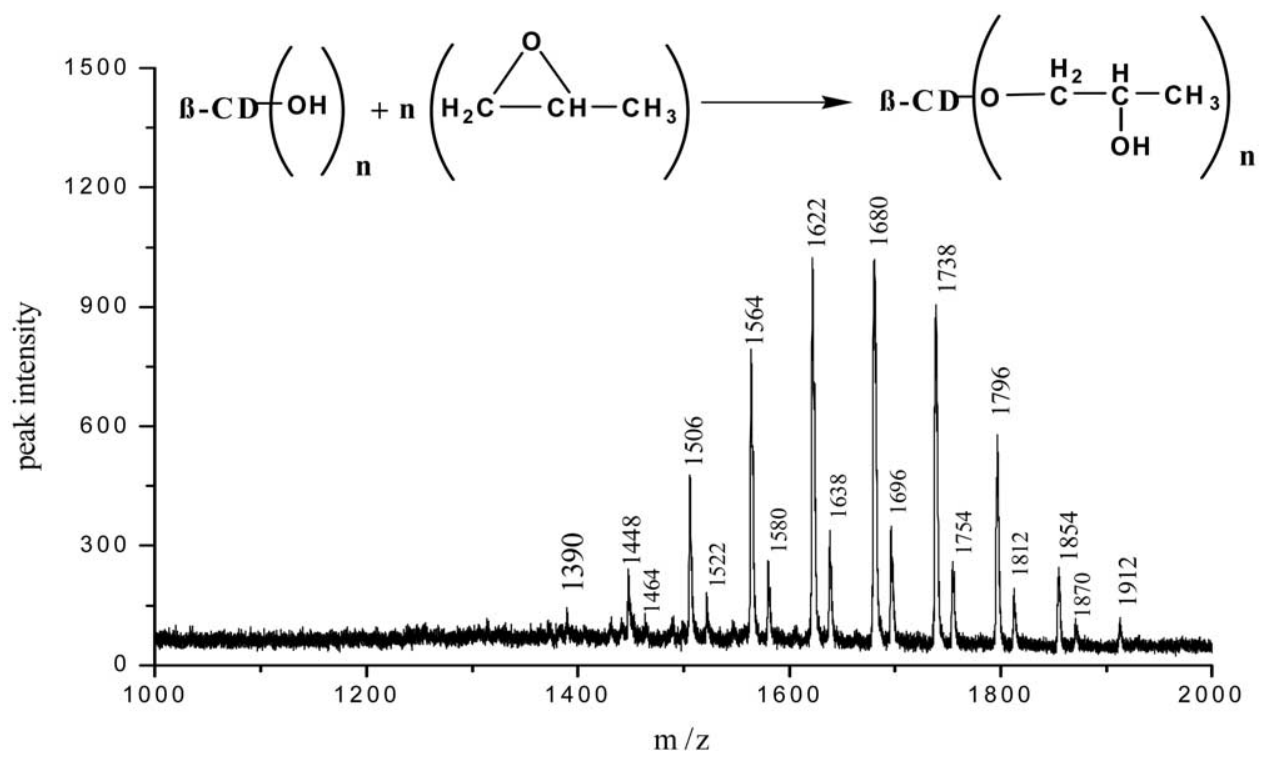

Figure 5. Mass spectrum of the synthetic product of $\beta-C D$ reacted with epoxy propane with matrix of oxidized carbon nanotubes. A series peaks of $m / z$ at 1391, 1449, 1507, 1565, 1623, 1681, 1739, 1797, 1855,1913 with an interval of 58 in $m / z$ are assigned to the $\mathrm{Na}^{+}$adduct ions for one molecule of $\beta$-CD reacted with $\mathrm{n}(\mathrm{n}=4,5,6, \ldots, 13)$ molecules of epoxy propane, and peaks of $m / z$ at $1465,1523,1581$, $1639,1697,1755,1813,1871$ are assigned to the $\mathrm{K}^{+}$adduct ions for one molecule of $\beta$-CD reacted with $n(n=5,6,7, \ldots, 12)$ molecules of epoxy propane.

palmatine at the concentration of $1 \mathrm{ng} / \mathrm{mL}(12 \%)$, which is probably caused by the factor that the concentration of analyte $(1 \mathrm{ng} / \mathrm{mL})$ is so far from the concentration of IS (100 $\mathrm{ng} / \mathrm{mL})$. The detection limit for berberine, jatrorrhizine, and palmatine are around $1 \mathrm{ng} / \mathrm{mL}$, i.e., approximately $3 \mathrm{fmol}$ with $\mathrm{S} / \mathrm{N} \approx 10$.

The quantitative result obtained with good linear calibration $\mathrm{R}^{2}$, wide linear ranges, and reliable reproducibility between sample spots, makes it possible to quantitatively determine the concentration of jatror- rhizine and palmatine simultaneously in practical sample through the standard addition method. For example, the mass spectrum of an extract of Coptis chinensis Franch with matrix of oxidized carbon nanotubes ${ }^{\circ}$ is $^{\circ}$ shown $^{\circ}$ in ${ }^{\circ}$ Figure $^{\circ} 7 .{ }^{\circ}$ Peaks $^{\circ}$ of $^{\circ} \mathrm{m} / z$ at ${ }^{\circ} 337,{ }^{\circ} 339$, and 353 could be assigned to the $\mathrm{H}^{+}$adduct ions of berberine, jatrorrhizine, and palmatine, respectively, and other peaks are left unidentified. The dominant peak of $\mathrm{m} / \mathrm{z}$ at 337 for berberine was selected as the IS for quantitative analysis of the concentration of ja-

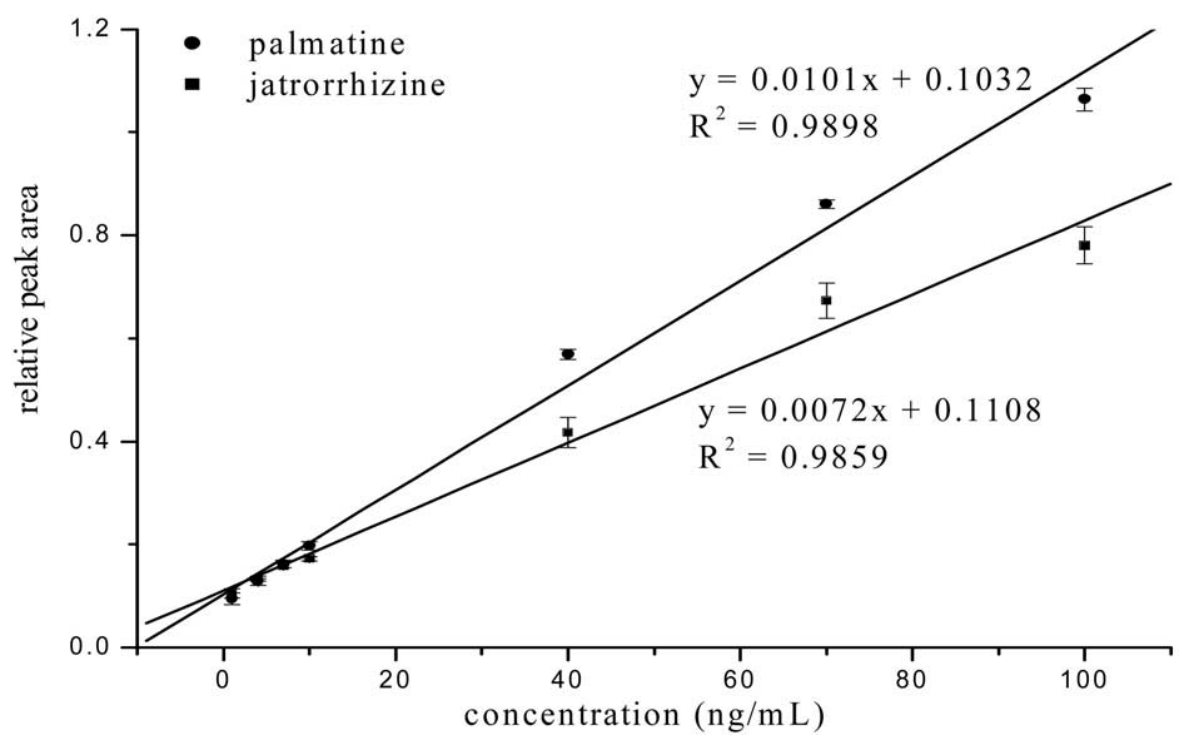

Figure 6. Quantitative calibration curves between the relative area $\left(\mathrm{A}_{\text {analytes }} / \mathrm{A}_{\mathrm{IS}}\right)$ of analyte peaks to IS peak ${ }^{\circ}$ and ${ }^{\circ}$ concentrations ${ }^{\circ}$ of analytes. ${ }^{\circ}$ Every ${ }^{\circ} \operatorname{dot}^{\circ}$ in ${ }^{\circ}$ Figure ${ }^{\circ} 6^{\circ} s^{\circ}$ obtained ${ }^{\circ} w^{\circ}$ th ${ }^{\circ}$ the $e^{\circ}$ average ${ }^{\circ}$ of ${ }^{\circ} 5^{\circ}$ spectra and each spectrum is accumulated from 20 laser shots at 10 different laser spots. 


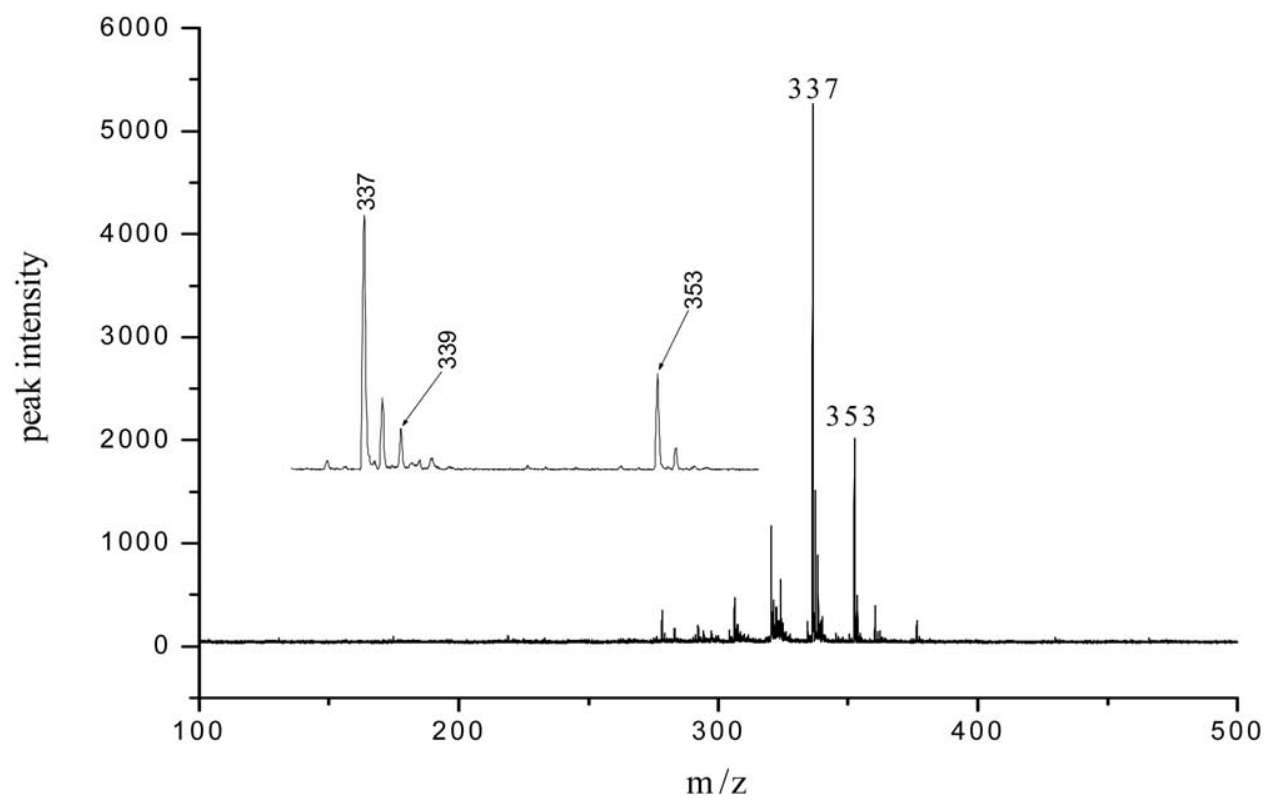

Figure 7. Mass spectrum of the extract of Coptis chinensis Franch with matrix of oxidized carbon nanotubes. Peaks of $\mathrm{m} / \mathrm{z}$ at 337, 339, and 353 are assigned to the $\mathrm{H}^{+}$adduct ions for berberine, jatrorrhizine, and palmatine, respectively.

trorrhizine $\left(339,[\mathrm{M}+\mathrm{H}]^{+}\right)$and palmatine $(353,[\mathrm{M}+$ $\mathrm{H}^{+}$). For the standard addition method, the extract of Coptis chinensis Franch was first diluted step by step for 6 orders of magnitude, and the absolute amount of analytes are added by varying from $0,5,10,15$, and $20 \mathrm{ng}$ in $1 \mathrm{~mL}$. Although the concentration of IS in the extract is not determined, it is satisfied to perform such a quantitative analysis as long as the concentration $^{\circ}$ of $^{\circ}$ IS $^{\circ}$ is $^{\circ}$ kept $^{\circ}$ constant. ${ }^{\circ}$ Figure $^{\circ} 8^{\circ}$ shows $^{\circ}$ the obtained quantitative calibration curves between the relative area $\left(\mathrm{A}_{\text {analytes }} / \mathrm{A}_{\mathrm{IS}}\right)$ of analyte peaks to IS peak and the absolute amount of analytes added. Every $^{\circ} \operatorname{dot}^{\circ}{ }^{\circ}{ }^{\circ}$ Figure $^{\circ} 8^{\circ}$ is $^{\circ}$ acquired ${ }^{\circ}$ in ${ }^{\circ}$ the ${ }^{\circ}$ same $^{\circ}$ way ${ }^{\circ}$ as the ${ }^{\circ} \operatorname{dot}^{\circ}$ in $^{\circ}$ Figure $^{\circ} 6 .^{\circ}$ The $^{\circ}$ values $^{\circ}$ of $^{\circ} \mathrm{R}^{2^{\circ}}$ for ${ }^{\circ}$ quantitative calibration curves of jatrorrhizine and palmatine are 0.9911 and 0.9947, respectively. According to the standard addition method and the calibration equations for jatrorrhizine and palmatine as shown in Figure $8{ }^{\circ}$, the $e^{\circ}$ intercep $t^{\circ}$ divided $^{\circ} b^{\circ}{ }^{\circ}$ the ${ }^{\circ}$ slope ${ }^{\circ}$ gives ${ }^{\circ}$ the absolute amounts of 8.65 and $10.4 \mathrm{ng}$ in $1 \mathrm{~mL}$ diluted solution for jatrorrhizine and palmatine, respectively. Then, the original concentration of jatrorrhizine and

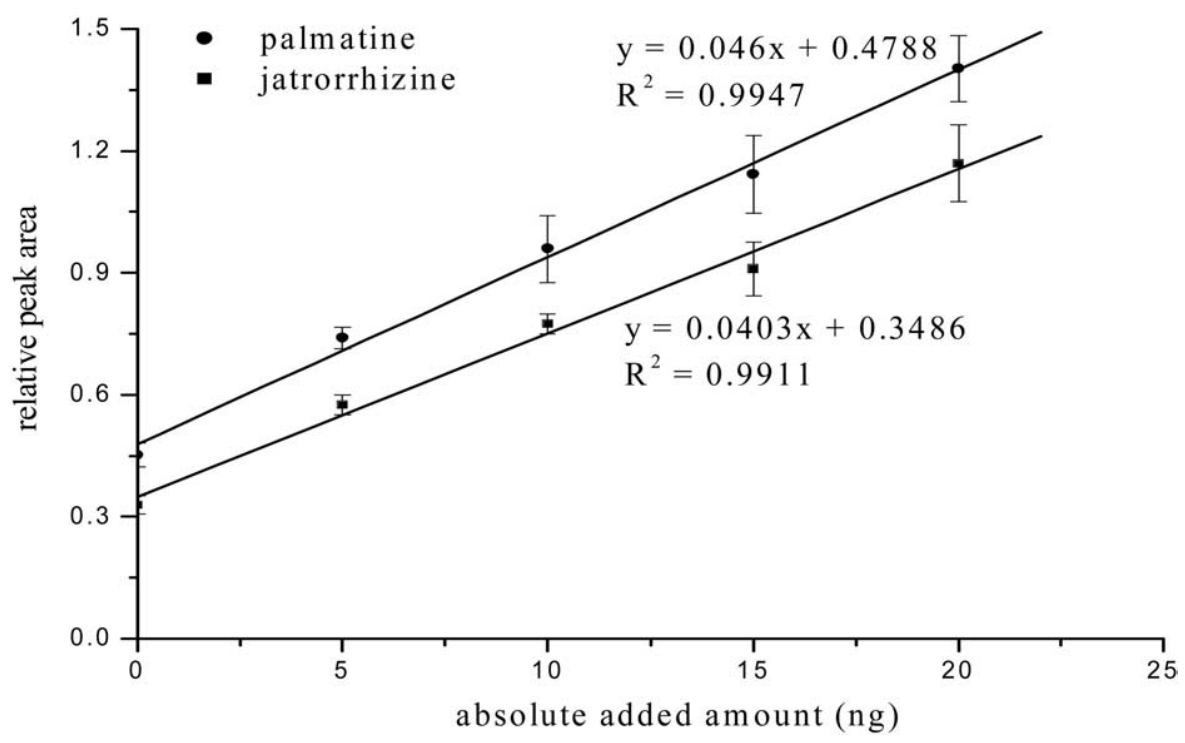

Figure 8. Quantitative calibration curves between the relative area $\left(\mathrm{A}_{\text {analytes }} / \mathrm{A}_{\mathrm{IS}}\right)$ of analyte peaks to IS peak and the absolute added amount of analytes. Every dot is the average of 5 spectra and each spectrum is accumulated from 20 laser shots at 10 different laser spots. 
palmatine in the extract of Coptis chinensis Franch are determined as 8.65 and $10.4 \mathrm{mg} / \mathrm{mL}$, respectively. The RSD values for each dot are all less than $10 \%$.

\section{Conclusion}

In this work, carbon nanotubes were oxidized and applied as matrix for MALDI-TOF-MS for analysis of small molecules. Compared with carbon nanotubes, the advantages of MALDI-TOF-MS with matrix of oxidized carbon nanotubes, including ease of sample preparation, more homogeneous and compact matrix layer, better efficiency of desorption/ionization for analytes, better reproducibility of peak intensities for analytes within and between sample spots, are all demonstrated. The matrix is successfully used for analysis of synthetic hydroxypropyl $\beta$-cyclodextrin, suggesting a great potential for monitoring reactions and for product quality control. Reliable quantitative analysis of jatrorrhizine and palmatine with a wide linear ranges (1-100 ng/mL) and good reproducibility within and between sample spots (RSD less than 10\%) are achieved. Above all, concentrations of jatrorrhizine $(8.65 \mathrm{mg} / \mathrm{mL})$ and palmatine $(10.4 \mathrm{mg} / \mathrm{mL})$ in an extract of Coptis chinensis Franch are determined simultaneously using the matrix and a standard addition method. It is believed that MALDI-TOF-MS with matrix of oxidized carbon nanotubes could be a powerful technique to provide both qualitative and quantitative determination of small compounds, such as amino acids, nucleotides, oligosaccharides, peptides drugs, and so on, in a practical, complex sample.

\section{Acknowledgments}

The authors gratefully acknowledge financial supports from the National Natural Sciences Foundation of China (no. 20327002), the China State Key Basic Research Program Grant (001CB510202 and 2003CB716002), the State High-Tech Program Grant (2003AA233061). HZ acknowledges the Knowledge Innovation program of DICP.

\section{References}

1. Karas, M.; Hillenkamp, F. Laser Desorption Ionization of Proteins with Molecular Masses Exceeding 10,000 Daltons. Anal. Chem. 1988, 60, 2299-2301.

2. Tanaka, M.; Waki, H.; Ido, Y.; Akita, S.; Yoshida, T. Protein and Polymer Analyses up to $m / z$ 10,000 by Laser Ionization Time-of-Flight Mass Spectrometry. Rapid Commun. Mass Spectrom. 1988, 2, 151-153.

3. Harvey, D. J. Matrix-Assisted Laser Desorption/Ionization Mass Spectrometry of Carbohydrates. Mass Spectrom. Rev. 1999, 18, 349-450.

4. Fenselau, C.; Demirev, P. A. Characterization of Intact Microorganisms by MALDI Mass Spectrometry. Mass Spectrom. Rev. 2001, 20, 157-171.

5. Lay, J. O. MALDI-TOF Mass Spectrometry of Bacteria. Mass Spectrom. Rev. 2001, 20, 172-194.

6. Tang, K.; Opalsky, D.; Abel, K.; van den Boom, D.; Yip, P.; Del Mistro, G.; Braun, A.; Cantor, C. R. Single Nucleotide Poly- morphism Analyses by MALDI-TOF MS. Int. J. Mass Spectrom. 2003, 226, 37-54.

7. Nielen, M. W. F. MALDI Time-of-Flight Mass Spectrometry of Synthetic Polymers. Mass Spectrom. Rev. 1999, 18, 309-344.

8. Cohen, L. H.; Gusev, A. I. Small Molecule Analysis by MALDI Mass Spectrometry. Anal. Bioanal. Chem. 2002, 373, 571-586.

9. Spengler, B. Post-Source Decay Analysis in Matrix-Assisted Laser Desorption/Ionization Mass Spectrometry of Biomolecules. J. Mass Spectrom. 1997, 32, 1019-1036.

10. Purcell, A. W.; Gorman, J. J. The Use of Post-Source Decay in Matrix-Assisted Laser Desorption/Ionization Mass Spectrometry to Delineate T Cell Determinants. J. Immunol. Methods 2001, 249, 17-31.

11. Talbo, G. H.; Suckau, D.; Malkoski, M.; Reynolds, E. C. MALDI-PSD-MS Analysis of the Phosphorylation Sites of Caseinomacropeptide. Peptides 2001, 22, 1093-1098.

12. Hoteling, A. J.; Owens, K. G. Improved PSD and CID on a MALDI TOFMS. J. Am. Soc. Mass Spectrom. 2004, 15, 523-535.

13. Cohen, L. H.; Gusev, A. I. Small Molecule Analysis by MALDI Mass Spectrometry. Anal. Bioanal. Chem. 2002, 373, 571-586.

14. Wei, J.; Buriak, J. M.; Siuzdak, G. Desorption-Ionization Mass Spectrometry on Porous Silicon. Nature 1999, 399, 243-246.

15. Lewis, W. G.; Shen, Z. X.; Finn, M. G.; Siuzdak, G. Desorption/ Ionization on Silicon (DIOS) Mass Spectrometry: Background and Applications. Int. J. Mass Spectrom. 2003, 226, 107-116.

16. Zhang, Q. C.; Zou, H. F.; Guo, Z.; Zhang, Q.; Chen, X. M.; Ni, J. Y. Matrix-Assisted Laser Desorption/Ionization Mass Spectrometry Using Porous Silicon and Silica Gel as Matrix. Rapid Commun. Mass Spectrom. 2001, 15, 217-223.

17. Zou, H. F.; Zhang, Q. C.; Guo, Z.; Guo, B.C; Zhang, Q.; Chen, X. M. A Mass Spectrometry Based Direct-Binding Assay for Screening Binding Partners of Proteins. Angew. Chem. Int. Ed. 2002, 114, 668-670.

18. Ayorinde, F. O.; Garvin, K.; Saeed, K. Determination of the Fatty Acid Composition of Saponified Vegetable Oils Using Matrix-Assisted Laser Desorption/Ionization Time-of-Flight Mass Spectrometry. Rapid Commun. Mass Spectrom. 2000, 14, 608-615.

19. Ayorinde, F. O.; Hambright, P.; Porter, T. N.; Keith, Q. L., Jr. Use of Meso-Tetrakis(Pentafluorophenyl)Porphyrin as a Matrix for Low Molecular Weight Alkylphenol Ethoxylates in Laser Desorption/Ionization Time-of-Flight Mass Spectrometry. Rapid Commun. Mass Spectrom. 1999, 13, 2474-2479.

20. Guo, Z.; Zhang, Q.; Zou, H.; Guo, B.; Ni, J. A Method for the Analysis of Low-Mass Molecules by MALDI-TOF Mass Spectrometry. Anal. Chem. 2002, 74, 1637-1641.

21. Sunner, J.; Dratz, E.; Chen, Y. C. Graphite Surface Assisted Laser Desorption/Ionization Time-of-Flight Mass-Spectrometry of Peptides and Proteins from Liquid Solutions. Anal. Chem. 1995, 67, 4335-4342.

22. Chen, Y. C.; Shiea, J.; Sunner, J. Thin-Layer Chromatography Mass Spectrometry Using Activated Carbon, Surface-Assisted Laser Desorption/Ionization. J. Chromatogr. A 1998, 826, 77-86.

23. Han, M.; Sunner, J. An Activated Carbon Substrate Surface for Laser Desorption Mass Spectrometry. J. Am. Soc. Mass Spectrom. 2000, 11, 644-649.

24. Chen, Y. C.; Shiea, J.; Sunner, J. Rapid Determination of Trace Nitrophenolic Organics in Water by Combining Solid-Phase Extraction with Surface-Assisted Laser Desorption/Ionization Time-of-Flight Mass Spectrometry. Rapid Commun. Mass Spectrom. 2000, 14, 86-90.

25. Xu, S. Y.; Li, Y. F.; Zou, H. F.; Qiu, J. S.; Guo, Z.; Guo, B. C. Carbon Nanotubes as Assisted Matrix for Laser Desorption/ Ionization Time-of-Flight Mass Spectrometry. Anal. Chem. 2003, 75, 6191-6195.

26. Muddiman, D. C.; Gusev, A. I.; Hercules, D. M. Application of Secondary Ion and Matrix-Assisted Laser Desorption-Ioniza- 
tion Time-of-Flight Mass Spectrometry for the Quantitative Analysis of Biological Molecules. Mass Spectrom. Rev. 1995, 14, 383-429.

27. Go, E. P.; Shen, Z. X.; Harris, K.; Siuzdak, G. Quantitative Analysis with Desorption/Ionization on Silicon Mass Spectrometry Using Electrospray Deposition. Anal. Chem. 2003, 75, 5475-5479.

28. Popov, V. N. Carbon Nanotubes: Properties and Application. Mater. Sci. Eng. R-Rep. 2004, 43, 61-102.

29. Lin, Y.; Taylor, S.; Li, H. P.; Fernando, K. A. S.; Qu, L. W.; Wang, W.; Gu, L. R.; Zhou, B.; Sun, Y. P. Advances Toward Bioapplications of Carbon Nanotubes. J. Mater. Chem. 2004, 14, 527-541.

30. Iijima, S. Helical Microtubules of Graphitic Carbon. Nature 1991, 354, 56-58.

31. Iijima, S.; Ichihashi, T. Single-Shell Carbon Nanotubes of 1-nm Diameter. Nature 1993, 363, 603-605.

32. Liu, J.; Rinzler, A. G.; Dai, H.; Hafner, J. H.; Bradley, R. K.;
Boul, P. J.; Lu, A.; Iverson, T.; Shelimov, K.; Huffman, C. B.; Rodriguez-Macias, F.; Shon, Y. S.; Lee, T. R.; Colbert, D. T.; Smalley, R. E. Fullerene Pipes. Science 1998, 280, 1253-1256.

33. Chen, J.; Hamon, M. A.; Hu, H.; Chen, Y. S.; Rao, A. M.; Eklund, P. C.; Haddon, R. C. Solution Properties of SingleWalled Carbon Nanotubes. Science 1998, 282, 95-98.

34. Fu, K. F.; Sun, Y. P. Dispersion and Solubilization of Carbon Nanotubes. J. Nanosci. Nanotechnol. 2003, 3, 351-364.

35. Ugarov, M. V.; Egan, T.; Khabashesku, D. V.; Schultz, J. A.; Peng, H. Q.; Khabashesku, V. N.; Furutani, H.; Prather, K. S.; Wang, H. W. J.; Jackson, S. N.; Woods, A. S. MALDI Matrices for Biomolecular Analysis Based on Functionalized Carbon Nanomaterials. Anal. Chem. 2004, 76, 67346742.

36. Chen, W. Y.; Wang, L. S.; Chiu, H. T.; Chen, Y. C.; Lee, C.Y. Carbon Nanotubes as Affinity Probes for Peptides and Proteins in MALDI MS Analysis. J. Am. Soc. Mass Spectrom. 2004, 15, 1629-1635. 